\title{
Ventilation Distribution, Pulmonary Diffusion and Peripheral Muscle Endurance as Determinants of Exercise Intolerance in Elderly Patients With Chronic Obstructive Pulmonary Disease
}

\author{
A. J. LOPES ${ }^{1,2}$, P. S. VIGÁRIO ${ }^{1}$, A. L. HORA ${ }^{1}$, C. A. L. DEUS ${ }^{1}$, M. S. SOARES ${ }^{3}$, \\ F. S. GUIMARÃES ${ }^{1}$, A. S. FERREIRA ${ }^{1}$ \\ ${ }^{1}$ Rehabilitation Sciences Post-Graduation Program, Augusto Motta University Center, Rio de Janeiro, \\ Brazil, ${ }^{2}$ Post-Graduation Program in Medical Sciences, School of Medical Sciences, State University \\ of Rio de Janeiro, Rio de Janeiro, Brazil, ${ }^{3}$ Admiral Adalberto Nunes Physical Education Center \\ (Brazilian Navy), Rio de Janeiro, Brazil
}

Received January 22, 2018

Accepted June 4, 2018

On-line September 11, 2018

\section{Summary}

Chronic obstructive pulmonary disease (COPD) is a progressive and disabling disease that has been associated with aging. Several factors may potentially impair performance during exercise in elderly patients with COPD. This study was conducted to evaluate what characteristics related to lung function, peripheral muscle strength and endurance can predict the performance of elderly patients with COPD during cardiopulmonary exercise testing (CPET). Forty elderly patients with COPD underwent resting lung function tests, knee isokinetic dynamometry, and CPET. Three models were developed to explain the variability in peak oxygen uptake $\left(\mathrm{VO}_{2}\right.$ peak) after controlling for age as an independent confounder. The pulmonary function model showed the highest explained variance $(65.6 \%)$; in this model, ventilation distribution $(p<0.001)$ and pulmonary diffusion (0.013) were found to be independent predictors. Finally, the models that included the muscle strength and endurance variables presented explained variances of $51 \%$ and $57.4 \%$, respectively. In these models that involved muscular dysfunction, however, only the endurance variables were found to be independent predictors $(p<0.05)$. In conclusion, ventilation distribution and pulmonary diffusion, but not the degree of airway obstruction, independently predict CPET performance in elderly patients with COPD. In addition, peripheral muscle endurance, but not strength, also predicts CPET performance in these subjects.

\section{Key words}

Chronic obstructive pulmonary disease - Aged - Functional capacity $\bullet$ Pulmonary function $\bullet$ Muscle function

\section{Corresponding author}

A. J. Lopes, Rehabilitation Sciences Post-Graduation Program, Augusto Motta University Center, Avenida Paris, 72, Bonsucesso, 21041-020, Rio de Janeiro, Brazil. E-mail: agnaldolopes.uerj@gmail.com

\section{Introduction}

There are many similarities between the lung aging process and chronic obstructive pulmonary disease (COPD), and many of the characteristics of aging are present in COPD, suggesting that accelerated aging may be a pathogenic mechanism in COPD (MacNee 2016). In fact, many of the changes that occur in the lungs with normal aging, such as declining lung function, deterioration of respiratory muscle strength, increased air trapping, loss of lung elastic recoil, and increased distal airspaces, are also present in COPD (MacNee 2016, van Wetering et al. 2008). Moreover, in the elderly population, the presence of cardiovascular, osteoarticular, and neurological abnormalities can lead to subclinical COPD symptoms and underdiagnosis of the disease. Therefore, routine evaluation using pulmonary function tests (PFTs) in elderly patients with risk factors for 
COPD are essential (Incalzi et al. 2014).

The loss of muscle strength and/or endurance is an important systemic effect of aging and drops sharply for aging associated with COPD (Evans et al. 2015, Maltais et al. 2014). These impairments have countless consequences in COPD patients, including low exercise tolerance, decreased quality of life, greater need for healthcare, and increased morbidity and mortality. Dysfunction of the lower limb muscles was even shown to better predict mortality than lung function measurements in COPD patients (Swallow et al. 2007). In recent years, isokinetic dynamometry has been used in clinical practice and is currently the standard method for assessing muscle function (Homem et al. 2017). However, to our knowledge, the contributions of the isokinetic tests have not been previously evaluated in the elderly populations with COPD.

In COPD, exercise intolerance is multifactorial. Exercise limitations reflect the reduced ventilatory capacity, abnormal gas exchange, and skeletal muscle dysfunction in these patients, especially for the muscles involved in walking. As a result, the exercise capacity and maximum work rate are reduced (Borghi-Silva et al. 2009). In this context, ventilatory limitation has been identified as one of the contributors to exercise intolerance, since those with COPD cease exercise because they cannot increase ventilation in response to increasing metabolic demands (O'Donnell 2001). Several factors determine ventilatory limitation during cardiopulmonary exercise testing (CPET), including abnormal ventilatory mechanics, increased ventilatory demand, and changes in the neuroregulatory control of breathing (O'Donnell 2001). In addition to ventilatory limitation, peripheral muscle dysfunction syndrome also seems to play a fundamental role in exercise intolerance in patients with COPD (Malaguti et al. 2011, Van't Hul et al. 2004). Some investigators have suggested that exercise intolerance is partly due to skeletal muscle dysfunction, and in $40-45 \%$ of COPD patients, muscle discomfort of the lower limbs is the main symptom that limits physical activity (Borghi-Silva et al. 2009). Despite these studies, this issue has not been addressed specifically in the elderly who suffer from COPD.

In elderly persons with COPD, exercise intolerance has a negative impact on the health-related quality of life (HRQL). Several factors may potentially impair performance during exercise in elderly patients with COPD, and understanding the mechanisms involved in functional capacity reduction may help identify new ways of approaching therapy and physical reconditioning for COPD. Thus, the objective of the present study was to evaluate what characteristics related to lung function, peripheral muscle strength and endurance can predict the performance of elderly patients with COPD during cardiopulmonary exercise testing (CPET).

\section{Material and Methods}

\section{Participants}

Between April 2015 and March 2017, a crosssectional study was conducted that evaluated 97 consecutive patients with COPD who were recruited at Newton Bethlem Hospital, Rio de Janeiro, Brazil. Only patients aged $\geq 60$ years were included. The diagnosis of COPD was established by spirometry showing a postbronchodilator forced expiratory volume in one second/forced vital capacity $\left(\mathrm{FEV}_{1} / \mathrm{FVC}\right)$ ratio of less than 0.7 and a smoking history of more than 10 packyears (GOLD 2018). Patients with history or radiographic evidence of tuberculosis, bronchiectasis or other pulmonary disorders, those taking oral prednisolone or undergoing supplemental oxygen therapy, those with respiratory exacerbations in the past four weeks, those undergoing pulmonary rehabilitation in the past 12 months, and those with any conditions that prevented CPET were excluded. The cases were classified as stages 1-4 (classification of airflow limitation severity) and A-D (assessment of symptoms and risk of exacerbations) according to the Global Initiative for Chronic Obstructive Lung Disease (GOLD) (2018). The project was approved by the Research Ethics Committee of the Augusto Motta University Center under number CAAE-52885116.6.0000.5235 and was in compliance with the provisions of the Declaration of Helsinki. All participants signed a consent form.

\section{Resting lung function}

Spirometry and the measurement of diffusion capacity of the lung for carbon monoxide (DLco) were carried out using a Collins Plus Pulmonary Function Testing System (Warren E. Collins, Inc., Braintree, MA, USA). DLco was measured using the single breath-hold method measurements with a rapidly responding gas analyzer, and the prediction values of DLco were adjusted according to hemoglobin levels (Graham et al. 2017). The $\mathrm{FEV}_{1}$ value was used to assess the degree of airway obstruction. Both PFTs followed the guidelines of the American Thoracic Society (Miller et al. 2005). Reference values for the Brazilian population were 
considered (Neder et al. 1999a, Pereira et al. 2007).

In addition, all participants performed a nitrogen

$\left(\mathrm{N}_{2}\right)$ single-breath washout (SBW) test using HDpft 3000 equipment (nSpire Health, Inc., Longmont, CO, USA), following standard recommendations (Robinson et al. 2013). Two parameters derived from the SBW test were analyzed, and both were interpreted as percentages of the predicted values (Buist and Ross 1973): the phase III slope of SBW ( $\left.\mathrm{SIII}_{\mathrm{N} 2}\right)$, which is defined as the change in the $\mathrm{N}_{2}$ concentration from $25-75 \%$ of the expired volume and considered a marker of ventilation distribution, and the closing volume/vital capacity (CV/VC) ratio, which is defined as the portion of the VC that is exhaled after the initiation of airway closure and is considered a marker of small airway disease (Lopes and Mafort 2014).

\section{Knee isokinetic dynamometry}

The quadriceps and hamstring muscles of the dominant lower limb were evaluated using a Biodex System 4 PRO dynamometer (Biodex Medical System, Shirley, NY, USA) at the Admiral Adalberto Nunes Physical Education Center (Brazilian Navy), Rio de Janeiro, Brazil. Briefly, the participants were seated in the equipment, and the trunk, pelvis, and thigh were stabilized using belts. The rotational axis of the dynamometer was aligned with the lateral epicondyle of the femur, while the range of motion for performing the test was set at $90^{\circ}$. Before the test, the patient underwent familiarization training with three submaximal repetitions (Homem et al. 2017, Lopes et al. 2016). After this step, strength analysis was performed through an angular velocity of $75 \%$ s with two sets of five repetitions. Subsequently, the participant performed the endurance evaluation through an angular velocity of $240 \%$ s with two sets of 15 repetitions (Justo et al. 2017). A rest period of two minutes was given between the tests. The highest value of the different repetitions of each of the following variables was analyzed: peak torque (PT), which is the maximum force produced at a given point of the range of motion (determined in extension) and was evaluated at $75 \%$ s $(\mathrm{PT} 75 \%$ s) and $240 \%$ (PT240\%), and agonist/antagonist ratio (AG/ANT), which is the PT of the hamstrings divided by $\mathrm{PT}$ of the quadriceps and was evaluated at $75 \%$ s (AG/ANT75\%) and at $240 \%$ s (AG/ANT240\%) (Walchan et al. 2016).

\section{Cardiopulmonary exercise testing}

CPET was performed on a treadmill (Inbramed, ATL, Porto Alegre, Brazil) as subject's respiratory gases were collected using a metabolic analyzer (MedGraphics
VO2000, Medical Graphics, Inc., St. Paul, MN, USA) that was operated according to standard procedures (American Thoracic Society/American College of Chest Physicians 2003). A ramp protocol with individualized incline and load was used. The capacity of each individual was adapted so that the duration of exercise intensity was between 8 and $12 \mathrm{~min}$, and the subsequent peak oxygen uptake $\left(\mathrm{VO}_{2}\right.$ peak) values were calculated. For interpretations of the $\mathrm{VO}_{2}$ peak, the reference values for the Brazilian population were considered (Neder et al. 1999b).

\section{Sample size}

Considering the association between the $\mathrm{VO}_{2}$ peak and pulmonary or muscle function variables as the main outcome of this study, a minimal sample size of 36 participants was necessary to observe a minimal correlation of 0.41 (weak or higher) at a $5 \%$ significance level and $80 \%$ study power.

\section{Statistical analysis}

Variables were described as the mean $\pm \mathrm{SD}$ or number (percentage) as appropriate. Bivariate associations were examined using the two-tailed Pearson's $r$ correlation coefficient between $\mathrm{VO}_{2}$ peak (\% predicted values) and clinical (age, sex ['male' $=1$ and 'female' $=0$ ], body mass index (BMI), pulmonary $\left(\mathrm{FEV}_{1}\right.$, DLco, $\operatorname{SIII}_{\mathrm{N} 2}$, and $\mathrm{CV} / \mathrm{VC}$ ), peripheral muscle strength $(\mathrm{PT} 75 \%$ and $\mathrm{AG} / \mathrm{ANT} 75 \%$ s) and endurance $(\mathrm{PT} 240 \% \mathrm{~s}$ and $\mathrm{AG} / \mathrm{ANT} 240 \%$ variables. Independent linear regression models were generated to explore the role of clinical, pulmonary, and peripheral muscle function variables as predictors of $\mathrm{VO}_{2}$ peak. Due to the proportion of the minimum number of variables per participant for developing prediction models (10:1) (Babyak 2004), our model included up to four independent variables simultaneously. We grouped variables to determine to what extent the independent predictors related to the same domain can predict the dependent variable. The models of muscle strength and endurance that were examined included age, gender, or BMI as covariates, provided they were identified as significantly correlated to $\mathrm{VO}_{2}$ peak. Because lung function variables were included as percentages of the predicted values (already considering general confounders), this model did include other covariates. The adjusted $\mathrm{R}^{2}$ and respective $p$-values as calculated from analysis of variance (ANOVA) tables were used to evaluate the fit of each model; regression coefficients and the respective $95 \%$ confidence intervals $(95 \% \mathrm{CIs})$ are 
also reported alongside the $p$-values. Multicollinearity was assessed using the variance inflation factor (VIF). Differences were considered statistically significant at $p<0.05$ with a $95 \%$ confidence interval. Analyses were conducted using SPSS 22 (SPSS, Chicago, IL, USA).

Table 1. Subject characteristics $(n=40)$.

\begin{tabular}{|c|c|}
\hline Variable & Values \\
\hline \multicolumn{2}{|l|}{ Demographics } \\
\hline Age (years) & $70.2 \pm 7.46$ \\
\hline Sex (male) & $21(52.5)$ \\
\hline$B M I\left(k g / m^{2}\right)$ & $23.7 \pm 5.07$ \\
\hline \multicolumn{2}{|l|}{ GOLD stages } \\
\hline $1-2$ & $20(50)$ \\
\hline $3-4$ & $20(50)$ \\
\hline$A-B$ & $17(42.5)$ \\
\hline$C-D$ & $23(57.5)$ \\
\hline \multicolumn{2}{|l|}{ Use of medications } \\
\hline$L A M A$ & $31(77.5)$ \\
\hline$L A B A$ & $24(60)$ \\
\hline$I C S$ & $15(37.5)$ \\
\hline \multicolumn{2}{|l|}{ Resting lung function } \\
\hline FEV1 (\% predicted) & $43.5 \pm 13.1$ \\
\hline DLco (\% predicted) & $43.1 \pm 13.7$ \\
\hline$S I I I_{N 2}(\%$ predicted $)$ & $302.9 \pm 192.7$ \\
\hline$C V / V C(\%$ predicted $)$ & $182.4 \pm 89.6$ \\
\hline \multicolumn{2}{|l|}{ Knee isokinetic dynamometry } \\
\hline$P T 75^{\circ} / \mathrm{s}$ & $89.6 \pm 27.4$ \\
\hline$A G / A N T 75^{\circ} / s$ & $54.1 \pm 15.9$ \\
\hline$P T 240^{\circ} / \mathrm{s}$ & $53.8 \pm 22.2$ \\
\hline$A G / A N T 240^{\circ} / s$ & $55.4 \pm 16.3$ \\
\hline \multicolumn{2}{|c|}{ Cardiopulmonary exercise testing } \\
\hline $\mathrm{VO}_{2}$ peak $(\%$ predicted $)$ & $53.3 \pm 18.5$ \\
\hline \multicolumn{2}{|c|}{ 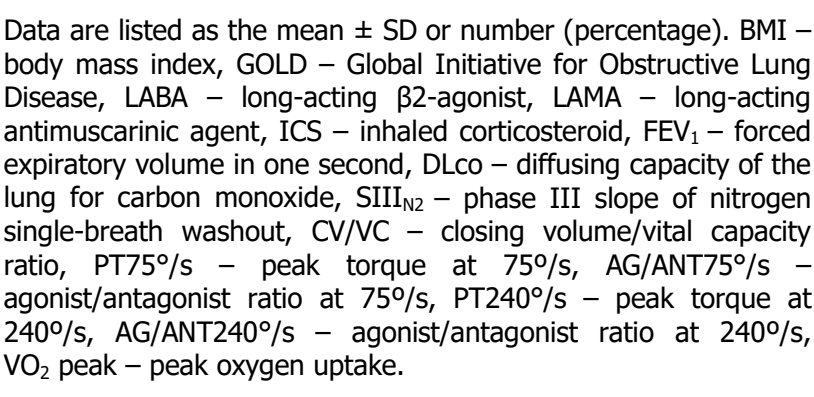 } \\
\hline
\end{tabular}

\section{Results}

\section{Subject characteristics}

Of the 97 participants eligible for evaluation, 40 completed the study (Fig. 1). The mean age was
$70.2 \pm 7.46$ years, and the smoking load was $45.2 \pm$ 19.8 pack-years. The clinical data, lung and muscle function, and CPET results are summarized in Table 1.

\section{Correlation analysis}

The $\mathrm{VO}_{2}$ peak was positively correlated with AG/ANT240\% $(r=0.574, p<0.001)$, PT240\% $/(r=0.552$, $p<0.001)$, DLco $(r=0.506, p=0.001), \mathrm{PT} 75 \%$ s $\quad(r=0.409$, $p=0.009), \mathrm{AG} / \mathrm{ANT} 75 \% \mathrm{~s}(r=0.401, p=0.010)$, and $\mathrm{FEV}_{1}$ $(r=0.396, p=0.012)$. Conversely, the $\mathrm{VO}_{2}$ peak was significantly negatively correlated with age $(r=-0.673$, $p<0.001)$ and $\mathrm{SIII}_{\mathrm{N} 2}(r=-0.557, p<0.001)$. Sex $(r=0.289$, $p=0.070), \quad \mathrm{BMI} \quad(r=-0.068, \quad p=0.676), \quad$ and $\mathrm{CV} / \mathrm{VC}$ $(r=0.007, p=0.968)$ were not significantly correlated with $\mathrm{VO}_{2}$ peak.

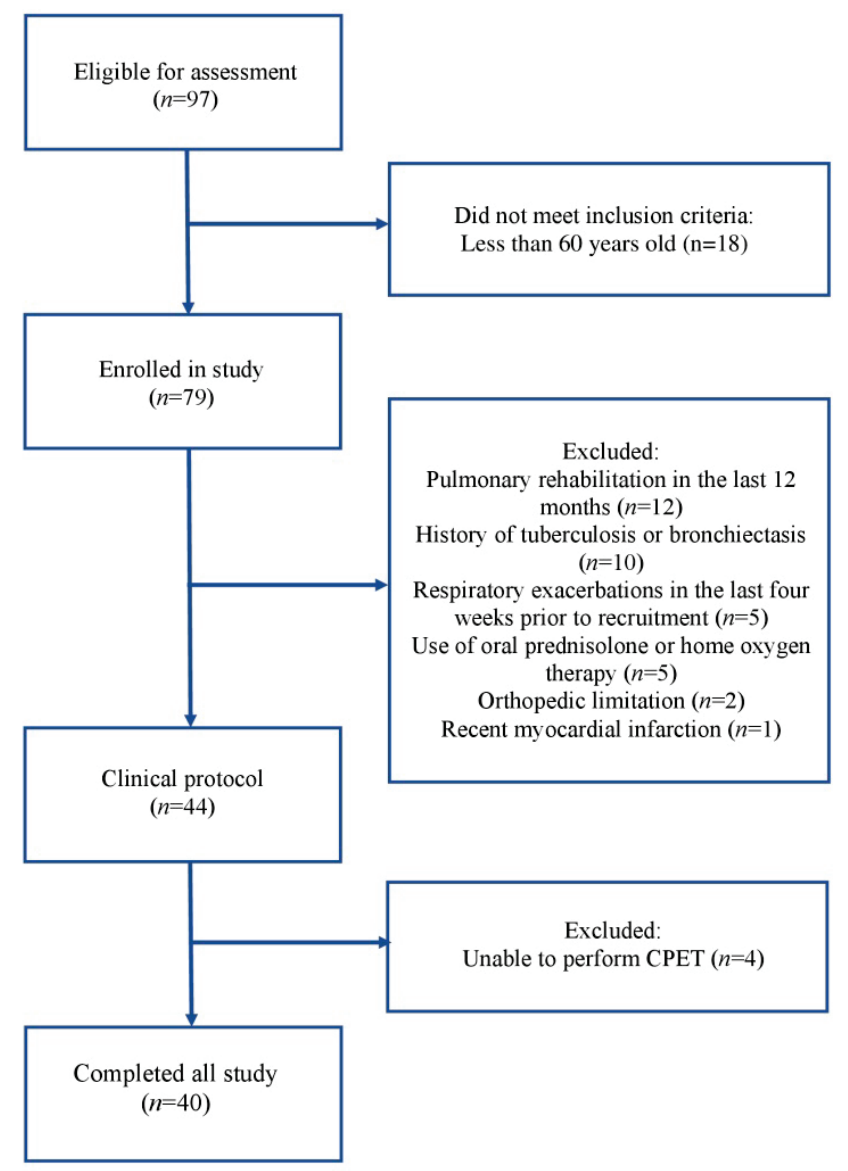

Fig. 1. Chart diagram indicating the flow of patients over the enrollment period.

Explaining the $\mathrm{VO}_{2}$ peak using clinical, pulmonary function, and peripheral muscle function variables

The average $\mathrm{VO}_{2}$ peak was significantly predicted by all models ( $p=0.008$ or lower). Tables 2 and 3 show the raw and adjusted models after controlling for possible confounders. Figures 2 and 3 show the 
regression plot for each tested model accordingly. The clinical model yielded an even higher explained variance (44.2\%), with age as the sole independent predictor negatively associated with $\mathrm{VO}_{2}$ peak $(p<0.001)$ identified in this analysis.

The model including peripheral muscle strength variables exhibited the lowest explained variance (19\%), whereas neither the PT nor AG/ANT at $75 \%$ s were independent predictors of $\mathrm{VO}_{2}$ peak ( $p=0.074$ or higher). After controlling for age, both PT and AG/ANT at $75 \% \mathrm{~s}$ were not independent predictors of $\mathrm{VO}_{2}$ peak $(p=0.125$ or higher). Conversely, the model including peripheral muscle endurance variables showed a higher explained variance $(42.8 \%$ ), and both PT and AG/ANT at $240 \%$ s were independent predictors positively associated with
$\mathrm{VO}_{2}$ peak ( $p=0.006$ or lower). After adjustment for age, both PT and AG/ANT at $240 \%$ s remained as independent predictors of $\mathrm{VO}_{2}$ peak ( $p=0.041$ or lower). Finally, the pulmonary function model showed the highest explained variance $\left(50.9 \%\right.$ ) in which $\mathrm{SIII}_{\mathrm{N} 2}$, DLco, and $\mathrm{FEV}_{1}$ ( $p=0.010$ or lower) but not CV/VC ( $p=0.170)$ were found to be independent predictors of $\mathrm{VO}_{2}$ peak. In this last model, $\mathrm{SIII}_{\mathrm{N} 2}$ was negatively associated with $\mathrm{VO}_{2}$ peak, whereas DLco and $\mathrm{FEV}_{1}$ were both positively associated. Multicollinearity was not identified in any model, as assessed by low VIF values (VIF=1.499 or lower). However, after adjustment for age only $\mathrm{SIII}_{\mathrm{N} 2}$ and DLco remained as independent predictors of $\mathrm{VO}_{2}$ peak ( $p=0.013$ or lower).

Table 2. Independent linear models of peak oxygen uptake (\% predicted) using muscle function, clinical, and pulmonary function $(n=40)$.

\begin{tabular}{|c|c|c|c|c|c|c|c|}
\hline Model & Variables & Adjusted $\mathbf{R}^{2}$ & SE of estimate & ANOVA & B $[95 \% C I]$ & VIF & $p$-value \\
\hline \multirow[t]{4}{*}{ Muscle strength } & & 0.190 & 16.899 & $F_{2,37}=5.567$ & & & 0.008 \\
\hline & Constant & & & & $21.279[0.724 ; 41.834]$ & & 0.043 \\
\hline & $P T 75^{\circ} / \mathrm{s}$ & & & & $0.162[-0.016 ; 0.340]$ & 1.211 & 0.074 \\
\hline & $A G / A N T 75 \% \mathrm{~s}$ & & & & $0.324[-0.049 ; 0.696]$ & 1.211 & 0.087 \\
\hline \multirow[t]{4}{*}{ Muscle endurance } & & 0.428 & 14.205 & $F_{2,37}=15.564$ & & & $<0.001$ \\
\hline & Constant & & & & $14.070[-0.933 ; 29.073]$ & & 0.065 \\
\hline & $P T 240 \% / s$ & & & & $0.323[0.101 ; 0.546]$ & 1.179 & 0.006 \\
\hline & $A G / A N T 240 \% s$ & & & & $0.395[0.146 ; 0.643]$ & 1.179 & 0.003 \\
\hline \multirow[t]{5}{*}{ Clinical } & & 0.442 & 14.021 & $F_{3,36}=11.310$ & & & $<\mathbf{0 . 0 0 1}$ \\
\hline & Constant & & & & $166.773[117.738 ; 215.808]$ & & $<0.001$ \\
\hline & Age & & & & $-1.595[-2.208 ;-0.981]$ & 1.035 & $<0.001$ \\
\hline & $\operatorname{Sex}$ & & & & $6.345[-2.814 ; 15.505]$ & 1.035 & 0.169 \\
\hline & Body mass & & & & $-0.204[-1.091 ; 0.683]$ & 1.001 & 0.644 \\
\hline \multirow[t]{6}{*}{ Pulmonary function } & & 0.509 & 13.161 & $F_{4,35}=11.091$ & & & $<0.001$ \\
\hline & Constant & & & & $23.754[0.190 ; 47.319]$ & & 0.048 \\
\hline & $S I I I_{N 2}$ & & & & $-0.057[-0.083 ;-0.030]$ & 1.499 & $<0.001$ \\
\hline & $D L c o$ & & & & $0.081[0.025 ; 0.137]$ & 1.420 & 0.006 \\
\hline & $F E V_{l}$ & & & & $0.490[0.123 ; 0.857]$ & 1.275 & 0.010 \\
\hline & $C V / V C$ & & & & $0.248[-0.111 ; 0.606]$ & 1.360 & 0.170 \\
\hline
\end{tabular}

Bold-formatted values represent statistical significance at level $p<0.05 . \mathrm{R}^{2}-$ determination coefficient, SE - standard error, ANOVA analysis of variance, $\mathrm{CI}$ - confidence interval, VIF - variance inflation factor, $\mathrm{PT} 75^{\circ} / \mathrm{s}-$ extension peak torque at $75^{\circ} / \mathrm{s}$, AG/ANT75\% agonist/antagonist ratio at $75 \%$ s, PT240\% - extension peak torque at $240 \%$ s, AG/ANT240\% - agonist/antagonist ratio at $240 \%$, SIII $_{\mathrm{N} 2}$ - phase III slope of nitrogen single-breath washout, DLco - diffusing capacity of the lung for carbon monoxide, FEV $\mathrm{V}_{1}$ - forced expiratory volume in one second, CV/VC - closing volume/vital capacity ratio. 
Table 3. Independent linear models of peak oxygen uptake (\% predicted) using muscle function and pulmonary function after controlling for age as independent confounder $(n=40)$.

\begin{tabular}{|c|c|c|c|c|c|c|c|}
\hline Model & Variables & Adjusted $\mathbf{R}^{2}$ & SE of estimate & ANOVA & B $[95 \% C I]$ & VIF & $p$-value \\
\hline \multirow[t]{5}{*}{ Muscle strength } & & 0.510 & 13.145 & $F_{3,36}=14.518$ & & & $<0.001$ \\
\hline & Constant & & & & $134.074[85.734 ; 182.414]$ & & $<0.001$ \\
\hline & $P T 75 \%$ s & & & & $0.102[-0.039 ; 0.243]$ & 1.248 & 0.151 \\
\hline & $A G / A N T 75 \% s$ & & & & $0.226[-0.066 ; 0.519]$ & 1.233 & 0.125 \\
\hline & Age & & & & $-1.455[-2.043 ;-0.867]$ & 1.083 & $<0.001$ \\
\hline \multirow[t]{5}{*}{ Muscle endurance } & & 0.574 & 12.248 & $F_{3,36}=18.547$ & & & $<0.001$ \\
\hline & Constant & & & & $105.117[53.698 ; 156.536]$ & & $<0.001$ \\
\hline & $P T 240 \% / s$ & & & & $0.211[0.009 ; 0.412]$ & 1.300 & 0.041 \\
\hline & $A G / A N T 240^{\circ} / s$ & & & & $0.270[0.045 ; 0.495]$ & 1.298 & 0.020 \\
\hline & Age & & & & $-1.112[-1.712 ;-0.504]$ & 1.333 & 0.001 \\
\hline \multirow[t]{7}{*}{ Pulmonary function } & & 0.656 & 11.012 & $F_{5,34}=15.872$ & & & $<0.001$ \\
\hline & Constant & & & & $119.932[67.223 ; 172.641]$ & & $<0.001$ \\
\hline & $S I I I_{N 2}$ & & & & $-0.051[-0.073 ;-0.028]$ & 1.526 & $<0.001$ \\
\hline & DLco & & & & $0.062[0.014 ; 0.110]$ & 1.481 & 0.013 \\
\hline & $F E V_{l}$ & & & & $0.318[-0.002 ; 0.637]$ & 1.378 & 0.051 \\
\hline & $C V / V C$ & & & & $0.041[-0.278 ; 0.359]$ & 1.527 & 0.797 \\
\hline & Age & & & & $-1.112[-1.678 ;-0.547]$ & 1.419 & $<0.001$ \\
\hline
\end{tabular}

Bold-formatted values represent statistical significance at level $p<0.05 . \mathrm{R}^{2}-$ determination coefficient, SE - standard error, ANOVA analysis of variance, CI - confidence interval, VIF - variance inflation factor, PT75\% $/ \mathrm{s}$ - extension peak torque at $75 \% \mathrm{~s}, \mathrm{AG} / \mathrm{ANT75} / \mathrm{s}-$ agonist/antagonist ratio at $75 \% / \mathrm{s}, \mathrm{PT} 240 \% \mathrm{~s}$ - extension peak torque at $240 \% \mathrm{~s}$, AG/ANT $240 \%$ s - agonist/antagonist ratio at $240 \% \mathrm{~s}$, $\mathrm{SIII}_{\mathrm{N} 2}$ - phase III slope of nitrogen single-breath washout, DLCo - diffusing capacity of the lung for carbon monoxide, FEV $_{1}-$ forced expiratory volume in one second, CV/VC - closing volume/vital capacity ratio.

\section{Discussion}

This study contributes the following new findings to our knowledge of systemic manifestations in elderly patients with COPD. Deterioration of lung function is the main contributor to poor performance during exercise in the elderly population with COPD. Thus, the greater the heterogeneity in the ventilation distribution and the decrease in pulmonary diffusion are, the lower the $\mathrm{VO}_{2}$ peak. In elderly people with COPD, muscle endurance (i.e. loss of the ability to sustain a specific task over time) but not muscle strength contributes strongly to exercise performance. In addition, older age was the only demographic variable that negatively impacted performance during the CPET.

The CPET provides an overview of the systems involved in transporting oxygen from ambient air to mitochondria and shows the performance of these systems during exercise. Among the four models we constructed before controlling for age as independent confounder (Table 2), the model including clinical variables presented an explained variance of almost $45 \%$ for $\mathrm{VO}_{2}$ peak, with age being the only independent predictor of $\mathrm{VO}_{2}$ peak. This finding is in line with those from a study by Betik and Hepple (2008), which demonstrated that $\mathrm{VO}_{2}$ peak decreases by an average of $10 \%$ per decade after the age of 30 due to the decreases in maximal heart rate, stroke volume, blood flow to skeletal muscle and skeletal muscle aerobic potential. Since the main feature of COPD is its progressive course with steadily increasing multisystem involvement (GOLD 2018), an even greater decline in $\mathrm{VO}_{2}$ peak is expected as aging progresses. In elderly patients with COPD, a reduced ability to perform physical exercise is a complicating factor and increases the mortality associated with COPD (Incalzi et al. 2014). Since age was the sole independent predictor negatively associated with peak $\mathrm{VO}_{2}(p<0.001)$, it is worth noting that the other models were then age-controlled as a confounding factor (Table 3). 

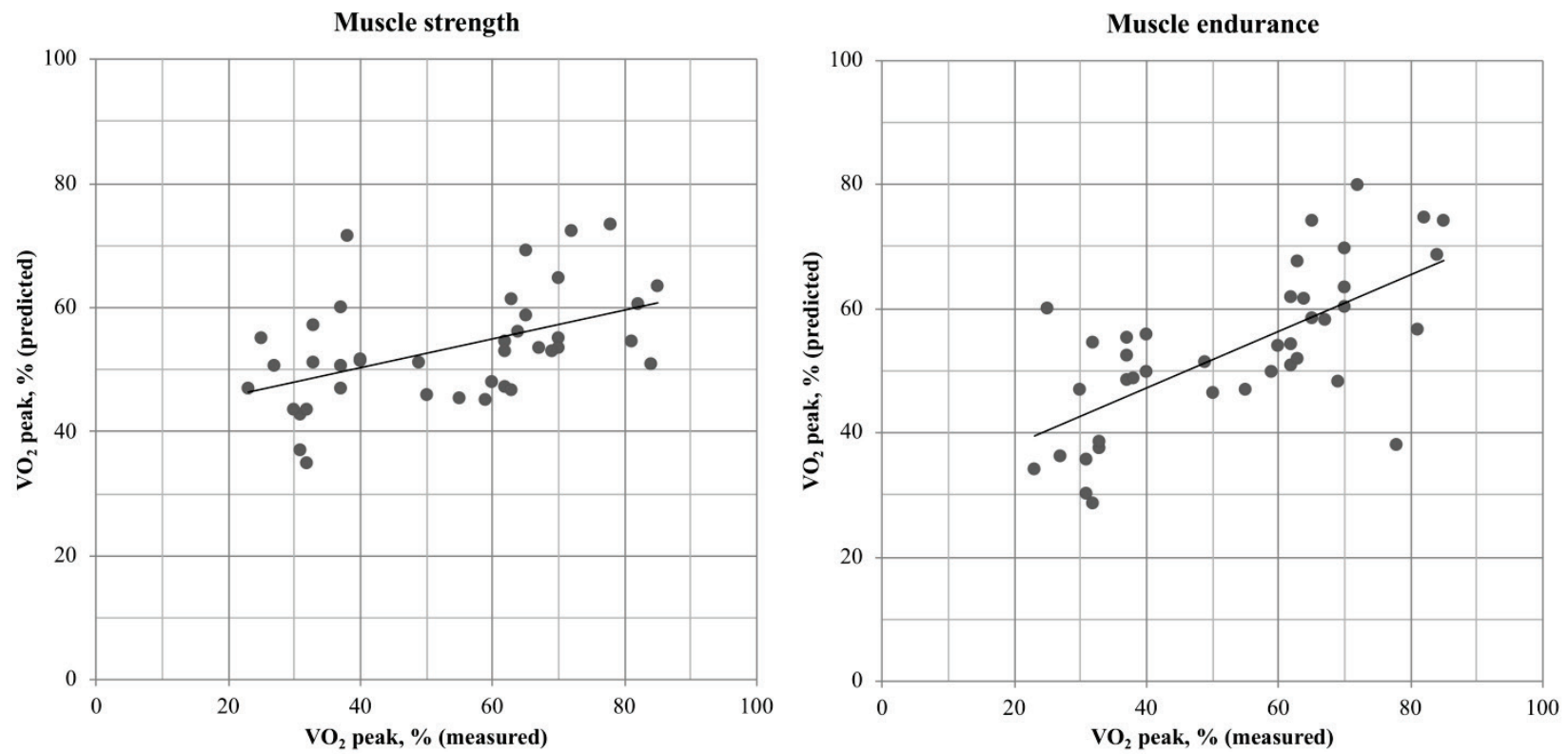

Clinical data
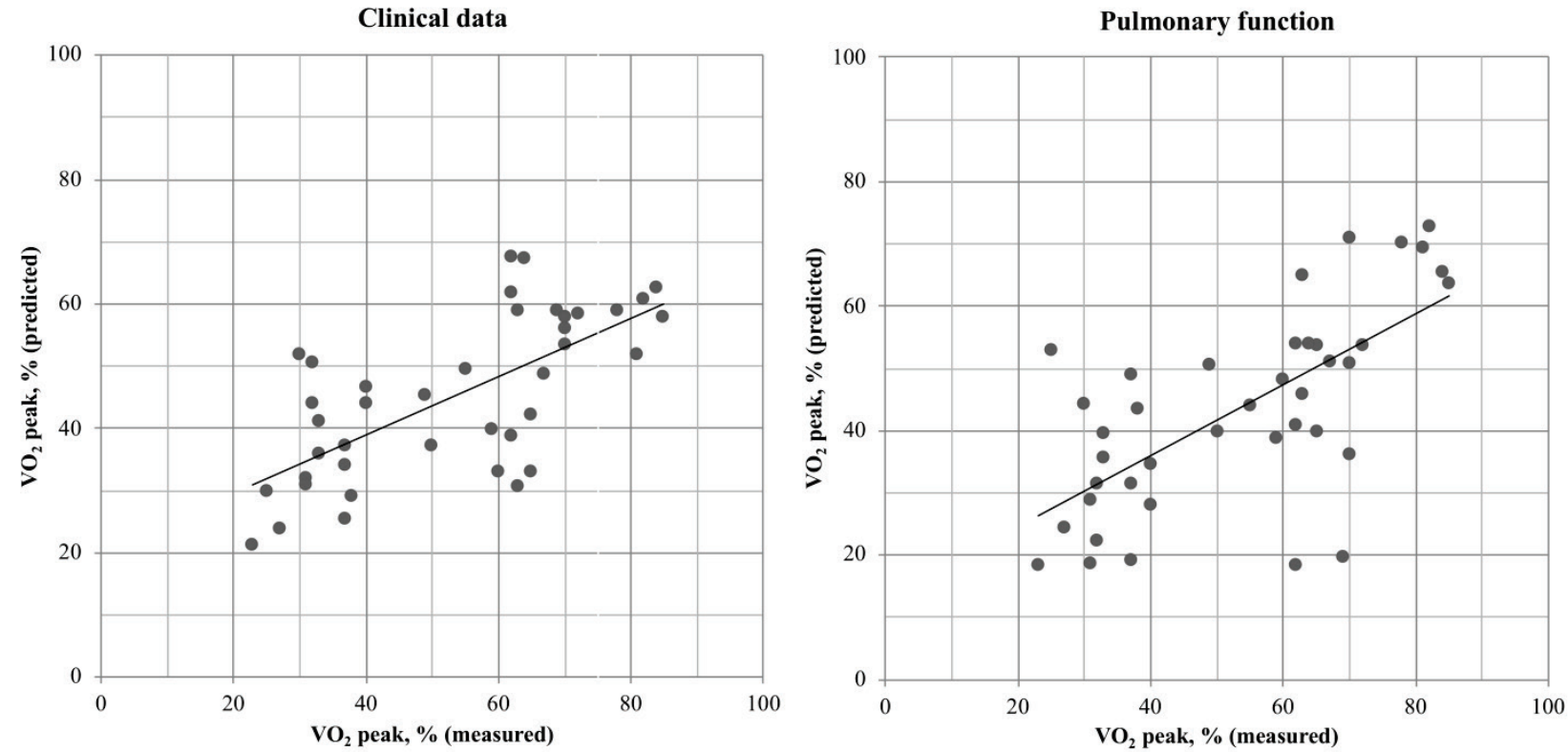

Fig. 2. Regression plots of the peak oxygen uptake $\left(\mathrm{VO}_{2}\right.$ peak) models (measured vs. predicted). The adjusted $\mathrm{R}^{2}$ for the models of $\mathrm{VO}_{2}$ peak were as follows: muscle strength, $R^{2}=0.190$; muscle endurance, $R^{2}=0.428$; clinical, $R^{2}=0.442$; and pulmonary function, $R^{2}=0.509$.

In COPD, increased ventilatory demand during exercise worsens air trapping and causes dynamic hyperinflation (DH) above the already increased resting volumes; $\mathrm{DH}$, in turn, compromises the ability of the inspiratory muscles to generate adequate intrathoracic pressures (O'Donnell 2001). In the present study, the pulmonary function model for elderly patients with COPD was the one that presented the highest explained variance for $\mathrm{VO}_{2}$ peak, surpassing $65 \%$ after controlling for age as an independent confounder. In this model, the pulmonary function variable that presented the greatest explanatory power was the elevation of $\mathrm{SIII}_{\mathrm{N} 2}$, which denotes heterogeneity in the ventilation distribution due to inefficient ventilation and greater ventilatory demand during exercise. Importantly, the main mechanism that generates alteration in ventilation comes from convection-dependent inhomogeneity in the conducting airway zone (i.e. airways proximal to terminal bronchioles), which contributes to an increased $\mathrm{SIII}_{\mathrm{N} 2}$ in SBW (Crawford et al. 1985, Robinson et al. 2013). In view of the difficulty of performing CPET in elderly patients with COPD because of the contraindications inherent to the test, we believe that SBW may contribute as a predictor of poor performance during exercise in these individuals (Lopes and Mafort 2014, Robinson et al. 2013). 

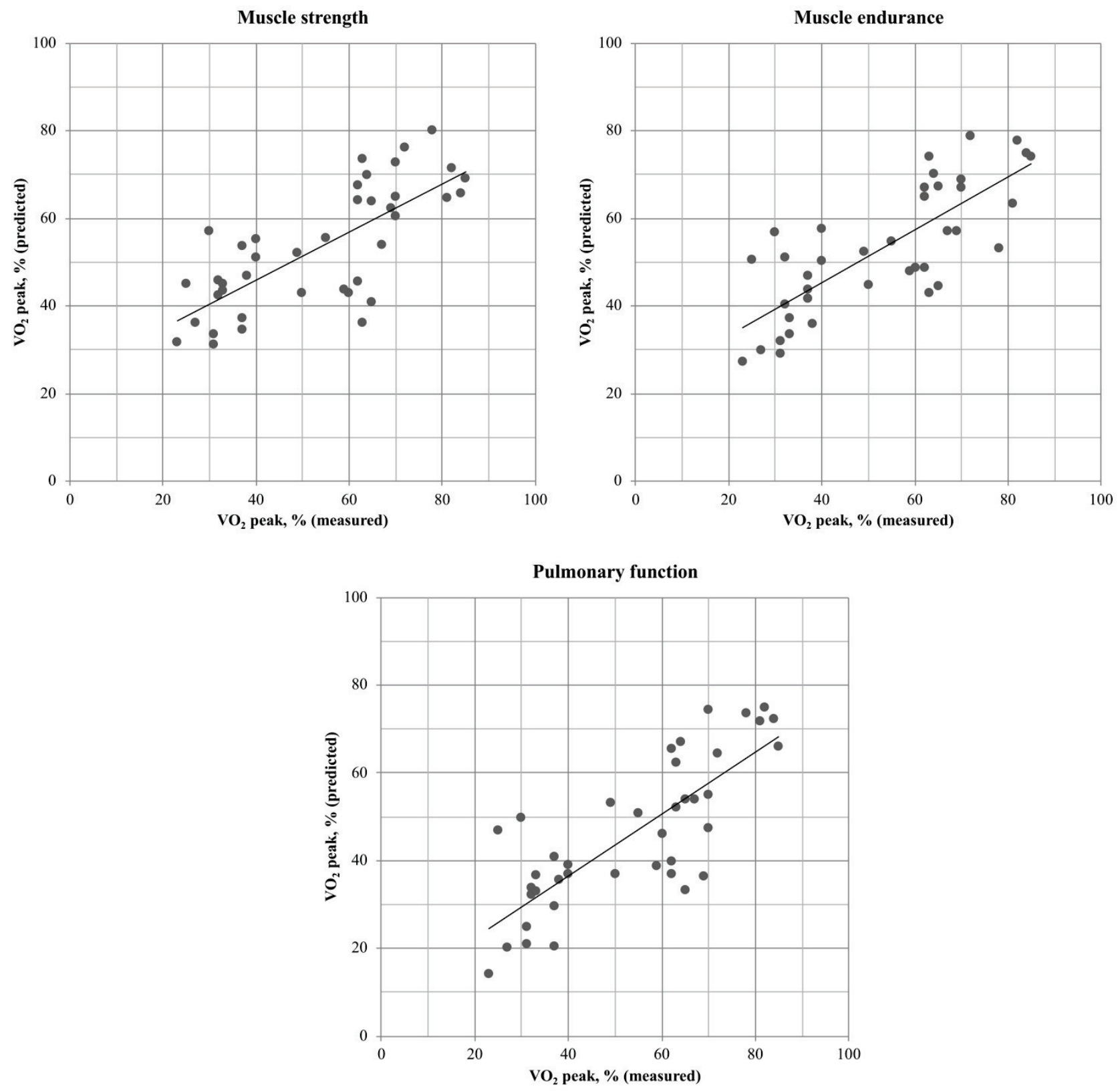

Fig. 3. Regression plots of the peak oxygen uptake $\left(\mathrm{VO}_{2}\right.$ peak) models (measured vs. predicted) after controlling for age as an independent confounder. The adjusted $\mathrm{R}^{2}$ for the models of $\mathrm{VO}_{2}$ peak were as follows: muscle strength, $\mathrm{R}^{2}=0.510$; muscle endurance, $\mathrm{R}^{2}=0.574$; and pulmonary function, $\mathrm{R}^{2}=0.656$.

Nevertheless, for our pulmonary function model proposed for elderly patients with COPD, the drop in pulmonary diffusion was also a predictor of reduced $\mathrm{VO}_{2}$ peak during exercise. Similar to our findings, Franssen et al. (2004) demonstrated that DLco, along with age and fat-free mass, explained $56 \%$ of the $\mathrm{VO}_{2}$ peak variance in COPD patients. Another study also found that DLco and quadriceps strength were independently associated with $\mathrm{VO}_{2}$ peak in these patients (van Wetering et al. 2008). In addition to varying with age, sex and height, DLco values also depend upon a number of physiological factors including hemoglobin levels, lung volume, carboxyhemoglobin, oxygen inspired tension, and exercise (Graham et al. 2017). Thus, our study provides further evidence that DLco may be a useful marker of exercise intolerance in elderly patients with COPD, especially in those with predominant emphysema and consequently reduced membrane surface area available for gas exchange (Neder et al. 2017). Interestingly, we also observed that $\mathrm{FEV}_{1}$ - the marker of the degree of airway obstruction most commonly used in clinical practice - did not enter our pulmonary function model after controlling for age as an independent confounder. Interestingly, the potential relationship 
between ventilatory inefficiency and exertional dyspnea in patients with symptomatic COPD and preserved FEV was already clearly established in a previous study (Franssen et al. 2004). This result reinforces the importance of a more detailed evaluation of lung function, in addition to $\mathrm{FEV}_{1}$, in this population of patients.

Muscle dysfunction in COPD shows a regional distribution, with relative preservation of muscle function of the trunk and upper limbs and deterioration of lower limb muscle function (Malaguti et al. 2011, Van't Hul et al. 2004). Thus, specific muscle groups of interest should be tested, since muscle weakness does not affect all muscles in a similar way, with variations depending on the anatomical region studied (Pleguezuelos et al. 2016, Robles et al. 2011). Using knee isokinetic dynamometry, we were able to demonstrate the negative impact of lower limb muscle dysfunction on $\mathrm{VO}_{2}$ peak in elderly patients with COPD. Potential factors contributing to agingrelated functional impairment in COPD patients include reduced motor neuron activity and changes in muscle morphology and energy metabolism leading to apoptosis, muscle atrophy, oxidative stress, reduced muscle capillarity, and intramuscular fat accumulation (Franssen et al. 2004, Robles et al. 2011). In addition, there are several adjuvant factors responsible for peripheral muscle dysfunction in these patients, including deconditioning/disuse, local inflammation, tissue hypoxia, hypercapnia, nutritional depletion, corticosteroid use, and hormonal changes, which promote structural and functional changes in contractile tissue (Evans et al. 2015, Janaudis-Ferreira et al. 2006, Maltais et al. 2014, Pleguezuelos et al. 2016, Robles et al. 2011). The relationship between lower limb muscle dysfunction and clinical outcomes in COPD suggests that clinical evaluation of muscle dysfunction in these patients may identify those at increased risk of exercise intolerance and premature death (Maltais et al. 2014).

Interestingly, the aging process may impact peripheral muscle function differently in individuals with COPD. In fact, our models that included the peripheral muscle function variables reached an explained variance of $\mathrm{VO}_{2}$ peak of $19 \%$ for muscle strength and $42.8 \%$ for muscle endurance. However, only the muscular endurance variables presented as independent predictors after controlling for age as a confounding factor $(p=0.041$ or lower). These differences can be justified at least in part by the significant deviation in the proportion of muscle fibers from type I to type II, the reduction in capillarity, and the altered metabolic enzyme levels (Borghi-Silva et al. 2009, van den Borst et al. 2013). In line with our findings, Malaguti et al. (2011) observed that in patients with COPD, muscle endurance and aerobic capacity are more greatly affected than muscle strength, even in patients with preserved muscle mass. However, there is no consensus about the main mechanisms involved in the decreasing muscle endurance in these patients. While one study showed that the impairment of quadriceps muscle endurance was associated with physical inactivity and the degree of pulmonary obstruction (Serres et al. 1998), another study demonstrated that quadriceps endurance was impaired independently of the level of physical activity (Coronell et al. 2004). More recently, Malaguti et al. (2011) reported that muscle atrophy seems to be the main determinant in the reduction of muscle strength among patients with COPD, whereas endurance reduction seems to be more related to the imbalance between oxygen supply and consumption due to low capillarity, bioenergetic abnormalities, and intrinsic alterations in the muscle contractility of the lower limbs.

Finally, in our muscle endurance model, both the reduction of the $\mathrm{PT} 240 \% \mathrm{~s}$ and the decrease in the $\mathrm{AG} / \mathrm{ANT} 240 \% \mathrm{~s}$ ratio contributed to the decrease in $\mathrm{VO}_{2}$ peak. The AG/ANT ratio is one of the parameters that has aroused great interest in isokinetics since this value describes the muscle balance in the knee joint. A change in the relationship between the PT of the hamstrings and the quadriceps indicates that there are excessive muscle imbalances, which predisposes the knee joint to injury (Walchan et al. 2016). Thus, lower limb training in elderly patients with COPD with consequent improvement in the AG/ANT ratio can provide several benefits, including greater exercise tolerance and better HRQL, since upper limb training has not shown the same benefits (Evans et al. 2015).

The strength of this study is that it is the first to evaluate the contribution of lung and muscle functions in exercise performance in elderly patients with COPD using the gold standard methods. However, like any study, ours also has limitations. First, we acknowledge that including GOLD stages as an independent variable to the pulmonary function model would be interesting from a clinical point of view. However, as related to lung function, our study focused on what variables predict CPET performance in patients with COPD. In this way, the inclusion of GOLD stages would not further understanding of the pathophysiologic mechanisms that 
may impair exercise tolerance in these subjects. Second, measurements of static lung volumes and peripheral muscle strength could possibly have contributed to increase the explained variance of the pulmonary function model for $\mathrm{VO}_{2}$ peak. Third, the inclusion of the six-minute walk test could have allowed the creation of models for distance traveled, since this test is much more commonly used in clinical practice due to its simplicity. Despite these limitations, our results may be important for establishing rehabilitation strategies for elderly patients with COPD, since the findings suggest that both lung function and lower limb muscle function play a prominent role in the functional capacity of these subjects. These results become even more significant when considering that only $20 \%$ of pulmonary rehabilitation programs use a detailed assessment of pulmonary and peripheral muscle function in COPD patients (Spruit et al. 2014).

In conclusion, the present study shows that ventilation distribution and pulmonary diffusion, but not the degree of airway obstruction, independently predict CPET performance in elderly patients with COPD. Aging has a differential impact on the lower limb muscle function in elderly patients with COPD, whereas peripheral muscle endurance but not strength also predicts CPET performance in these subjects. In addition, older age is the main demographic variable that reduces functional capacity during exercise in the elderly population with COPD.

\section{Conflict of Interest}

There is no conflict of interest.

\section{Acknowledgements}

This research was supported by the Brazilian Council for Scientific and Technological Development (CNPq) and Rio de Janeiro State Research Supporting Foundation (FAPERJ).

\section{References}

AMERICAN THORACIC SOCIETY/AMERICAN COLLEGE OF CHEST PHYSICIANS: ATS/ACCP statement on cardiopulmonary exercise testing. Am J Respir Crit Care Med 167: 211-277, 2003.

BABYAK MA: What you see may not be what you get: a brief, nontechnical introduction to overfitting in regressiontype models. Psychosom Med 66: 411-421, 2004.

BETIK AC, HEPPLE RT: Determinants of $\mathrm{VO}_{2}$ max decline with aging: an integrated perspective. Appl Physiol Nutr Metab 33: 130-140, 2008.

BORGHI-SILVA A, Di THOMMAZO L, PANTONI CB, MENDES RG, SALVINI TF, COSTA D: Non-invasive ventilation improves peripheral oxygen saturation and reduces fatigability of quadriceps in patients with COPD. Respirology 14: 537-544, 2009.

BUIST AS, ROSS BB: Predicted values for closing volumes using a modified single breath nitrogen test. Am Rev Respir Dis 107: 744-752, 1973.

CORONELL C, OROZCO-LEVI M, MENDEZ R, RAMIREZ-SARMIENTO A, GALDIZ JB, GEA J: Relevance of assessing quadriceps endurance in patients with COPD. Eur Respir J 24: 129-136, 2004.

CRAWFORD AB, MAKOWSKA M, PAIVA M, ENGEL LA: Convection- and diffusion-dependent ventilation maldistribution in normal subjects. J Appl Physiol 59: 838-846, 1985.

EVANS RA, KAPLOVITCH E, BEAUCHAMP MK, DOLMAGE TE, GOLDSTEIN RS, GILLIES CL, BROOKS D, MATHUR S: Is quadriceps endurance reduced in COPD? A systematic review. Chest 147: 673-684, 2015.

FRANSSEN FM, BROEKHUIZEN R, JANSSEN PP, WOUTERS EF, SCHOLS AM: Effects of whole-body exercise training on body composition and functional capacity in normal-weight patients with COPD. Chest 125: 2021-2028, 2004.

GOLD - GLOBAL INITIATIVE FOR CHRONIC OBSTRUCTIVE LUNG DISEASE: Global strategy for the diagnosis, management and prevention of chronic obstructive pulmonary disease. http://www.goldcopd.org/. Accessed 10 January 2018.

GRAHAM BL, BRUSASCO V, BURGOS F, COOPER BG, JENSEN R, KENDRICK A, MACINTYRE NR, THOMPSON BR, WANGER J: 2017 ERS/ATS standards for single-breath carbon monoxide uptake in the lung. Eur Respir J 49: 1600016, 2017. 
HOMEM T, GUIMARÃES FS, SANTOS MS, KASUKI L, GADELHA MR, LOPES AJ: Balance control and peripheral muscle function in aging: a comparison between individuals with acromegaly and healthy subjects. J Aging Phys Act 25: 218-227, 2017.

INCALZI RA, SCARLATA S, PENNAZZA G, SANTONICO M, PEDONE C: Chronic obstructive pulmonary disease in the elderly. Eur J Intern Med 25: 320-328, 2014.

JANAUDIS-FERREIRA T, WADELL K, SUNDELIN G, LINDSTRÖM B: Thigh muscle strength and endurance in patients with COPD compared with healthy controls. Respir Med 100: 1451-1457, 2006.

JUSTO AC, GUIMARÃES FS, FERREIRA AS, SOARES MS, BUNN PS, LOPES AJ: Muscle function in women with systemic sclerosis: association with fatigue and general physical function. Clin Biomech 47: 33-39, 2017.

LOPES AJ, MAFORT TT: Correlations between small airway function, ventilation distribution, and functional exercise capacity in COPD patients. Lung 192: 653-659, 2014.

LOPES AJ, FERREIRA AS, WALCHAN EM, SOARES MS, BUNN PS, GUIMARÃES FS: Explanatory models of muscle performance in acromegaly patients evaluated by knee isokinetic dynamometry: implications for rehabilitation. Hum Mov Sci 49: 160-169, 2016.

MACNEE W: Is chronic obstructive pulmonary disease an accelerated aging disease? Ann Am Thorac Soc 13 (Suppl 5): S429-S437, 2016.

MALAGUTI C, NAPOLIS LM, VILLAÇA D, NEDER JA, NERY LE, DAL CORSO S: Relationship between peripheral muscle structure and function in patients with chronic obstructive pulmonary disease with different nutritional status. J Strength Cond Res 25: 1795-1803, 2011.

MALTAIS F, DECRAMER M, CASABURI R, BARREIRO E, BURELLE Y, DEBIGARÉ R, DEKHUIJZEN PN, FRANSSEN F, GAYAN-RAMIREZ G, GEA J, GOSKER HR, GOSSELINK R, HAYOT M, HUSSAIN SN, JANSSENS W, POLKEY MI, ROCA J, SAEY D, SCHOLS AM, SPRUIT MA, STEINER M, TAIVASSALO T, TROOSTERS T, VOGIATZIS I, WAGNER PD, ATS/ERS AD HOC COMMITTEE ON LIMB MUSCLE DYSFUNCTION IN COPD: An official American Thoracic Society/European Respiratory Society statement: update on limb muscle dysfunction in chronic obstructive pulmonary disease. Am J Respir Crit Care Med 189: e15-e62, 2014.

MILLER MR, HANKINSON J, BRUSASCO V, BURGOS F, CASABURI R, COATES A, CRAPO R, ENRIGHT P, VAN DER GRINTEN CP, GUSTAFSSON P, JENSEN R, JOHNSON DC, MACINTYRE N, MCKAY R, NAVAJAS D, PEDERSEN OF, PELLEGRINO R, VIEGI G, WANGER J; ATS/ERS TASK FORCE. Standardisation of spirometry. Eur Respir J 26: 319-338, 2005.

NEDER JA, ANDREONI S, PERES C, NERY LE: Reference values for lung function tests III. Carbon monoxide diffusing capacity (transfer factor). Braz J Med Biol Res 32: 729-737, 1999a.

NEDER JA, NERY LE, CASTELO A, ANDREONI S, LERARIO MC, SACHS A, SILVA AC, WHIPP BJ: Prediction of metabolic and cardiopulmonary responses to maximum cycle ergometry: a randomized study. Eur Respir J 14: 1304-1313, 1999b.

NEDER JA, BERTON DC, MÜLLER PT, ELBEHAIRY AF, ROCHA A, PALANGE P, O'DONNELL DE, CANADIAN RESPIRATORY RESEARCH NETWORK: Ventilatory inefficiency and exertional dyspnea in early chronic obstructive pulmonary disease. Ann Am Thorac Soc 14 (Suppl 1): S22-S29, 2017.

O'DONNELL DE: Ventilatory limitations in chronic obstructive pulmonary disease. Med Sci Sports Exerc 33 (7 Suppl): S647-S655, 2001.

PEREIRA CA, SATO T, RODRIGUES SC: New reference values for forced spirometry in white adults in Brazil. J Bras Pneumol 33: 397-406, 2007.

PLEGUEZUELOS E, ESQUINAS C, MORENO E, GUIRAO L, ORTIZ J, GARCIA-ALSINA J, MERÍ A, MIRAVITLLES M: Muscular dysfunction in COPD: systemic effect or deconditioning? Lung 194: 249-257, 2016.

ROBINSON PD, LATZIN P, VERBANCK S, HALL GL, HORSLEY A, GAPPA M, THAMRIN C, ARETS HG, AURORA P, FUCHS SI, KING GG, LUM S, MACLEOD K, PAIVA M, PILLOW JJ, RANGANATHAN S, RATJEN F, SINGER F, SONNAPPA S, STOCKS J, SUBBARAO P, THOMPSON BR, GUSTAFSSON PM: Consensus statement for inert gas washout measurement using multiple- and single- breath tests. Eur Respir $J$ 41: 507-522, 2013. 
ROBLES PG, MATHUR S, JANAUDIS-FEREIRA T, DOLMAGE TE, GOLDSTEIN RS, BROOKS D: Measurement of peripheral muscle strength in individuals with chronic obstructive pulmonary disease: a systematic review. J Cardiopulm Rehabil Prev 31: 11-24, 2011.

SERRES I, GAUTIER V, VARRAY A, PREFAUT C: Impaired skeletal muscle endurance related to physical inactivity and altered lung function in COPD patients. Chest 113: 900-905, 1998.

SPRUIT MA, PITTA F, GARVEY C, ZUWALLACK RL, ROBERTS CM, COLLINS EG, GOLDSTEIN R, MCNAMARA R, SURPAS P, ATSUYOSHI K, LÓPEZ-CAMPOS JL, VOGIATZIS I, WILLIAMS JE, LAREAU S, BROOKS D, TROOSTERS T, SINGH SJ, HARTL S, CLINI EM, WOUTERS EF; ERS REHABILITATION AND CHRONIC CARE, AND PHYSIOTHERAPISTS SCIENTIFIC GROUPS; AMERICAN ASSOCIATION OF CARDIOVASCULAR AND PULMONARY REHABILITATION; ATS PULMONARY REHABILITATION ASSEMBLY AND THE ERS COPD AUDIT TEAM: Differences in content and organisational aspects of pulmonary rehabilitation programmes. Eur Respir J 43: 1326-1337, 2014.

SWALLOW EB, REYES D, HOPKINSON NS, MAN WD, PORCHER R, CETTI EJ, MOORE AJ, MOXHAM J, POLKEY MI: Quadriceps strength predicts mortality in patients with moderate to severe chronic obstructive pulmonary disease. Thorax 62: 115-120, 2007.

VAN DEN BORST B, SLOT IG, HELLWIG VA, VOSSE BA, KELDERS MC, BARREIRO E, SCHOLS AM, GOSKER HR: Loss of quadriceps muscle oxidative phenotype and decreased endurance in patients with mildto-moderate COPD. J Appl Physiol 114: 1319-1328, 2013.

VAN WETERING CR, VAN NOOTEN FE, MOL SJ, HOOGENDOORN M, RUTTEN-VAN MÖLKEN MP, SCHOLS AM: Systemic impairment in relation to disease burden in patients with moderate COPD eligible for a lifestyle program. Findings from the INTERCOM trial. Int J Chron Obstruct Pulmon Dis 3: 443-451, 2008.

VAN'T HUL A, HARLAAR J, GOSSELINK R, HOLLANDER P, POSTMUS P, KWAKKEL G: Quadriceps muscle endurance in patients with chronic obstructive pulmonary disease. Muscle Nerve 29: 267-274, 2004.

WALCHAN EM, GUIMARÃES FS, SOARES MS, PINHO LKJ, GADELHA MR, LOPES AJ: Parameters of knee isokinetic dynamometry in individuals with acromegaly: association with growth hormone levels and general fatigue. Isokinet Exerc Sci 24: 331-340, 2016. 